\title{
Over-Expression of TSC-22 (TGF- $\beta$ Stimulated Clone-22) Markedly Enhances 5-Fluorouracil-Induced Apoptosis in a Human Salivary Gland Cancer Cell Line
}

\author{
Daisuke Uchida, Hitoshi Kawamata, Fumie Omotehara, Yoshihiro Miwa, \\ Satoshi Hino, Nasima-Mila Begum, Hideo Yoshida, and Mitsunobu Sato
}

Second Department of Oral and Maxillofacial Surgery (DU, HK, FO, SH, NMB, HY, MS) and Department of Biochemistry (YM), Tokushima University School of Dentistry, Tokushima, Japan

\begin{abstract}
SUMMARY: We have recently isolated TSC-22 (transforming growth factor- $\beta$-stimulated clone-22) cDNA as an anticancer, drug-inducible (with vesnarinone) gene in a human salivary gland cancer cell line, TYS. We have also reported that TSC-22 negatively regulates the growth of TYS cells and that down-regulation of TSC-22 in TYS cells plays a major role in salivary gland tumorigenesis (Nakashiro et al, 1998). In this study, we transfected TYS cells with an expression vector encoding the TSC-22-GFP (green fluorescent protein) fusion protein, and we established TSC-22-GFP-expressing TYS cell clones. Next, we examined (a) the subcellular localization of the fusion protein, (b) the sensitivity of the transfectants to several anticancer drugs (5-fluorouracil, cis-diaminedichloroplatinum, peplomycin), and (c) induction of apoptotic cell death in the transfectants by 5-fluorouracil treatment. The TSC-22-GFP fusion protein was clearly localized to the cytoplasm, but not to the nucleus. Over-expression of the TSC-22-GFP fusion protein did not affect cell growth, but significantly increased the sensitivity of the cells to the anticancer drugs $(p<0.01$; one-way ANOVA). Furthermore, over-expression of the TSC-22-GFP fusion protein markedly enhanced 5-fluorouracilinduced apoptosis. These findings suggest that over-expression of TSC-22-GFP protein in TYS cells enhances the chemosensitivity of the cells via induction of apoptosis. (Lab Invest 2000, 80:955-963).
\end{abstract}

$W$ have recently isolated human transforming growth factor- $\beta$-stimulated clone-22 (TSC-22) cDNA as an anticancer, drug-inducible (with vesnarinone) gene in a human salivary gland cancer cell line, TYS (Kawamata et al, 1998). We have also reported that TSC-22 negatively regulates the growth of TYS cells (Kawamata et al 1998) and that down-regulation of TSC-22 in TYS cells plays a major role in salivary gland tumorigenesis (Nakashiro et al, 1998). TSC-22 was originally reported to be a transforming growth factor- $\beta$ (TGF- $\beta$ )-inducible gene that encodes a putative transcriptional regulator containing a leucine zipper-like structure in mouse osteoblastic cells, MC3T3E1 (Shibanuma et al, 1992). Separately, Hamil and Hall (1994) isolated the rat TSC-22 gene as a follicle-stimulating hormone (FSH)-inducible gene in Sertoli cells. Delta-sleep-inducing peptide-like immunoreactive peptide, which was purified from pig, also showed homology to TSC-22 protein (Sillard et al, 1993; Vogel et al, 1996). Treisman et al (1995) isolated a Drosophila gene, shortsighted, which had homology to the mouse and rat TSC-22 genes. They reported

Received March 8, 2000.

This study was supported in part by a grant-in-aid from the Ministry of Education, Science and Culture of Japan.

Address reprint requests to: Dr. Hitoshi Kawamata, Second Department of Oral and Maxillofacial Surgery, Tokushima University School of Dentistry, 3-18-15 Kuramoto, Tokushima 770-8504, Japan. Fax: +81-88-6337462;E-mail:kawamata@dent.tokushima-u.ac.jp that shortsighted acted in the decapentaplegic pathway in the development of the Drosophila eye (Treisman et al, 1995). Subsequently, Kania et al (1995) found that shortsighted was an allele of bunched, which was required for development of the embryonic peripheral nervous system. Moreover, Dobens et al (1997) noted that the Drosophila bunched gene was required for the proper elaboration of dorsal cell fates, leading to the formation of the dorsal appendages.

When we isolated human TSC-22 cDNA, Jay et al (1992) and Ohta et al (1996) independently isolated and reported the full sequence of human TSC-22 cDNA. Jay et al (1996) identified its chromosomal localization at 13q14. Ohta et al (1996) reported TSC-22 as a transcription factor for the C-type natriuretic peptide gene promoter. Subsequently, Ohta et al (1997) noted that over-expression of the TSC-22 gene in a human gastric carcinoma cell line induced apoptotic cell death via activation of Caspase-3. Kester et al (1997) identified human TSC-22 as a progesterone target gene that was associated with progesterone-induced growth inhibition and enhancement of the differentiation of breast cancer cells. However, the precise molecular mechanisms of the action of TSC-22 on cell growth and differentiation were not fully understood.

In this study, to clarify the role of TSC-22 in the growth of human salivary gland cancer cells, we transfected TYS cells with an expression vector encoding the TSC-22-GFP-fusion protein, and we estab- 
lished several TSC-22-green fluorescent protein (GFP) fusion protein-expressing clones. Next, we examined (a) the subcellular localization of the fusion protein; (b) the sensitivity of the transfected-clones to three anticancer drugs: 5-fluorouracil (5-FU), cis-diaminedichloroplatinum (CDDP), peplomycin (PEP); and (c) the induction of apoptotic cell death in the cell clones by 5-FU.

\section{Results}

\section{Expression and Localization of TSC-22-GFP Fusion Protein in the Transfectants}

TYS cells that were transiently transfected with pEGFP-TSC-22 (Fig. 1) showed green fluorescent protein (GFP) fluorescence only in the cytoplasm, but not in the nucleus, whereas TYS cells that were transfected with pEGFP-C3 showed GFP fluorescence in both cytoplasm and nucleus (Fig. 2, A and B). After cultivation with selective medium containing G418 for 2 weeks, we randomly isolated eight clones in TSC-22-GFP transfectants and four clones in control GFP transfectants. Most of the G418-resistant clones showed GFP fluorescence. Then we selected two clones, TYS-TSC-22-GFP-H and TYS-TSC-22GFP-L, in TSC-22-GFP transfectants and one clone, TYS-GFP, in GFP transfectants as controls for further experiments. In stable TSC-22-GFP transfectants, GFP fluorescence was localized only in the cytoplasm, but not in the nucleus (Fig. 2C). On the other hand, in a stable GFP transfectant, GFP fluorescence was localized in both the cytoplasm and nucleus (Fig. 2D). GFP fluorescence in TYS-TSC-22-GFP-H was more intense than that in TYS-TSC-22-L, and the intensity of GFP fluorescence in control TYS-GFP was similar to that in TYS-TSC-22-GFP-H (data not shown). It was generally recognized that the intensity of GFP fluores- cence in the transfectants was proportional to the level of the fusion protein. Therefore, it can be concluded that TYS-TSC-22-GFP-H expresses a higher level of TSC-22-GFP fusion protein than does TYSTSC-22-GFP-L.

We further confirmed the expression of TSC-22GFP fusion proteins in the transfectants by Western blot analysis. We detected a $45 \mathrm{kDa}$ protein by an anti-TSC-22 antibody only in TYS-TSC-22-GFP-H, but not in parental TYS or control TYS-GFP (Fig. 3). The molecular weight of TSC-22 is $18 \mathrm{kDa}$ and that of GFP is $27 \mathrm{kDa}$; therefore, the $45 \mathrm{kDa}$ protein is thought to be a TSC-22-GFP fusion protein. Furthermore, a very faint band at approximately $130 \mathrm{kDa}$ was observed in TYS-TSC-22-GFP-H cells.

\section{In Vitro Chemosensitivity of the Cell Clones}

We evaluated the relative cell number in each cell clone at Days 0,4 , and 8 by comparing the absorbance that was determined by 3-(4, 5-dimethylthiazol-2-yl)-2, 5-diphenyltetrazolium bromide (MTT) assay. No significant difference was seen in the growth potential among the cell clones either in the absence (Fig. 4A) or in the presence of fetal calf serum (FCS) (data not shown). However, transfected TSC-22-GFP markedly enhanced the chemosensitivity of TYS cells to all of the drugs tested (Fig. 4, B to D; Table 1). 5-FU treatment $(1 \mu \mathrm{g} / \mathrm{ml}$ or $10 \mu \mathrm{g} / \mathrm{ml}$ ) suppressed the growth of parental cells down to $20 \%$ at Day 2 and $10 \%$ at Day 4; however, almost all of the TSC-22-GFP-H cells were killed at Day 2 by treatment with $1 \mu \mathrm{g} / \mathrm{ml}$ or $10 \mu \mathrm{g} / \mathrm{ml}$ of $5-\mathrm{FU}$ (Fig. 4B). Low concentrations of CDDP $(0.5 \mu \mathrm{g} / \mathrm{ml})$ and PEP $(0.15 \mu \mathrm{g} / \mathrm{ml})$ markedly suppressed the growth of TYSTSC-22-GFP-H and TYS-TSC-22-GFP-L cells, whereas they had little effect on the parental TYS cells and control TYS-GFP cells (Fig. 4, C and D). We summarized $\mathrm{IC}_{50}$ for

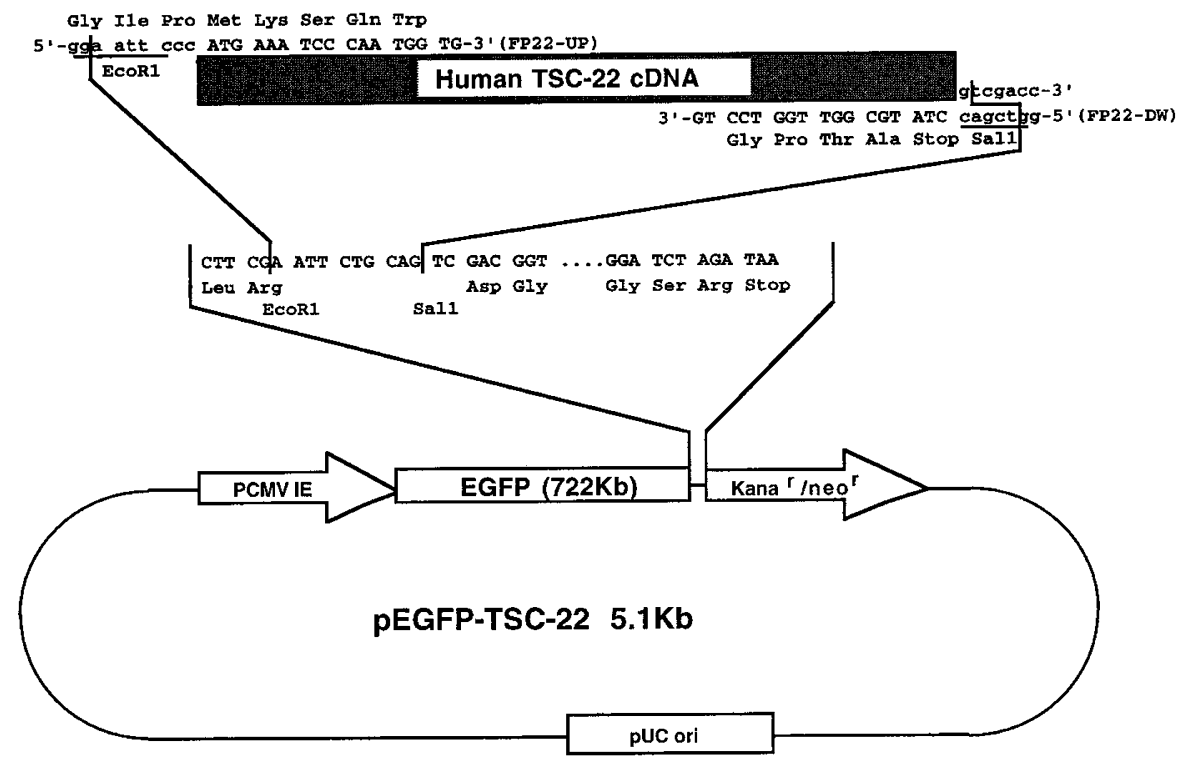

Figure 1.

pEGFP-TSC-22 plasmid construction. The plasmid pEGFP-TSC-22 contains the enhanced green fluorescent protein (GFP)-human TSC-22 fusion gene under the transcriptional control of the cytomegalovirus immediate early promoter (CMV-IE). 

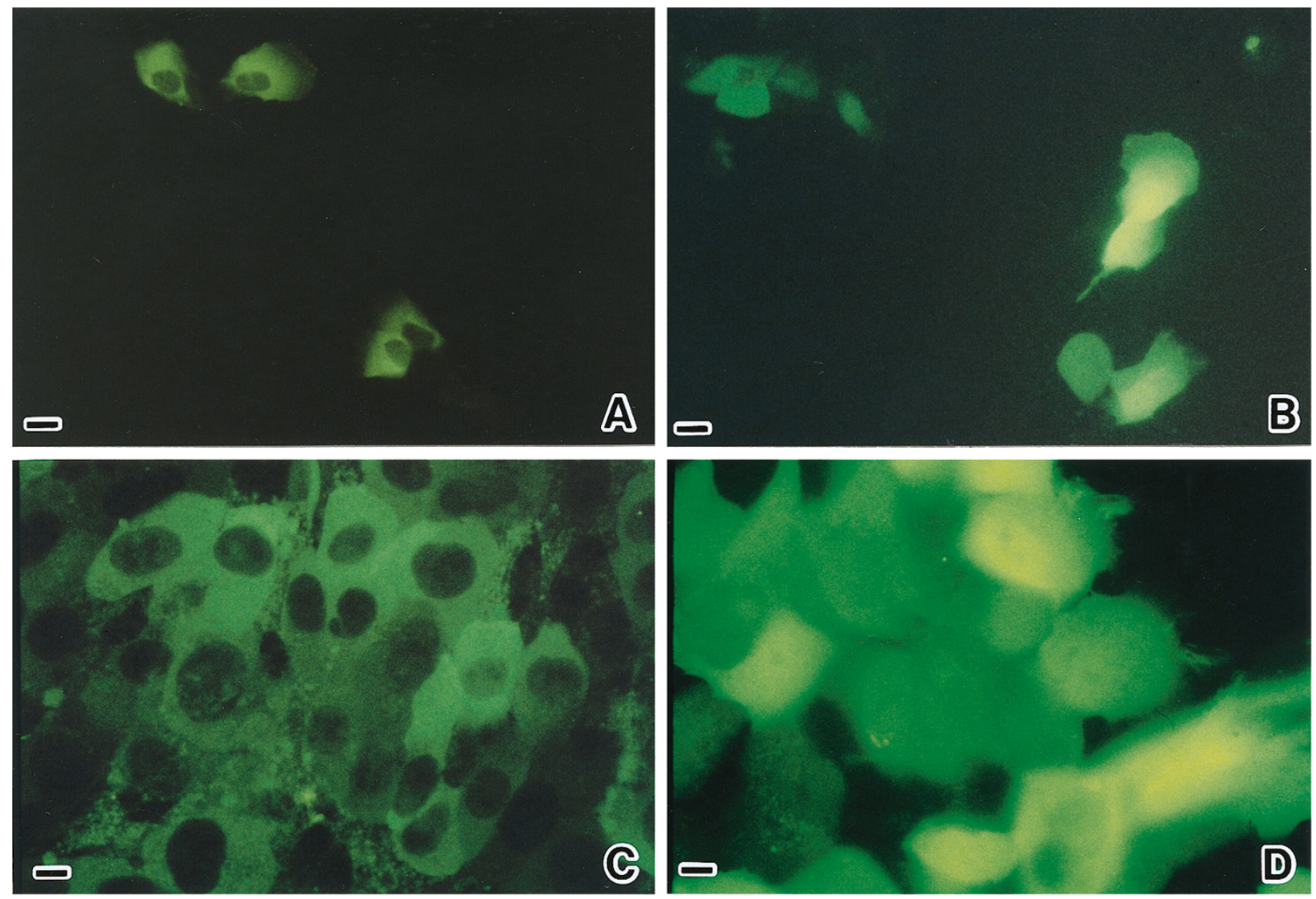

\section{Figure 2.}

Expression and localization of TSC-22-GFP fusion protein in the transfectants. GFP fluorescence in the transfectants was observed by fluorescence microscopy excited by $495 \mathrm{~nm}$ blue light. In TSC-22-GFP transfectants ( $A$ and $C$ ), GFP fluorescence (TSC-22-GFP fusion protein) was localized only to the cytoplasm but not to the nucleus in both transient $(A)$ and stable transfectants $(C)$, whereas, in control GFP transfectants $(B$ and $D)$, GFP fluorescence was localized not only to the cytoplasm, but also to the nucleus in both transient $(B)$ and stable transfectants $(D)$. Bar, $20 \mu \mathrm{m}(A, B), 10 \mu \mathrm{m}(C, D)$.

5-FU, PEP, and CDDP of parental TYS cells, control cells, and TSC-22-expressing transfectants in Table 1. High-expression of TSC-22 protein markedly enhanced the sensitivity of TYS cells to 5-FU (Table 1). Either high or moderate expression of TSC-22 protein enhanced the sensitivity of TYS cells to PEP, as well as to CDDP (Table 1).

\section{Induction of Apoptosis in 5-FU-Treated Cells}

5-FU treatment induced the apoptosis of parental TYS cells as well as of TYS-TSC-22-GFP cell clones, as was shown by the formation of chromatin condensation on Hoechst 33258 staining (Fig. 5). Of the attached cells, $8 \%$ of TYS-GFP-22-GFP-H cells showed chromatin condensation after treatment with $1 \mu \mathrm{g} / \mathrm{ml}$ of $5-\mathrm{FU}$ for 24 hours, whereas only $2 \%$ of control TYS-GFP cells showed chromatin condensation (Fig. 5 , A and C). Of the floating cells, $80 \%$ of TYS-GFP22-GFP-H cells showed chromatin condensation, whereas only $20 \%$ of control TYS-GFP cells did so (Fig. 5, B and D).

\section{Effect of Antisense Oligonucleotide against the TSC-22 Gene on TYS-TSC-22-GFP Cells}

Treatment of TYS-TSC-22-GFP-H cells with an antisense oligonucleotide at $30 \mu \mathrm{m}$ clearly inhibited the expression of transfected TSC-22-GFP protein (Fig. $6 \mathrm{~A})$. However, treatment with a sense oligonucleotide at the same concentration did not affect the expression of the fusion protein (Fig. 6A). Furthermore, the antisense oligonucleotide significantly restored the survival of the cells to 5 -FU ( $p<0.001$; one-way ANOVA) (Fig. 6B). 5-FU (1 $\mu \mathrm{g} / \mathrm{ml})$ treatment inhibited the growth of TYS-TSC-22-GFP-H cells down to $50 \%$ of control at Day 2; however, the antisense oligonucleotide restored the cell number up to $80 \%$ of control, even in the presence of 5-FU. On the other hand, the antisense oligonucleotide marginally influenced the effect of 5-FU on parental TYS cells.

\section{Discussion}

In our previous transfection experiment (Nakashiro et al, 1998), we demonstrated that down-regulation of TSC-22 enhanced the growth of TYS cells in vitro and in vivo. However, up-regulation of TSC-22 did not affect the growth of TYS cells either in vitro or in vivo (Nakashiro et al, 1998). In that experiment, we mixed all of the G418-resistant colonies together in each sense or antisense transfectant, and we examined in vitro growth and tumorigenicity. Thus, the experiment was not performed at the clonal cell level. Each G418-resistant clone in the transfectants may express 
(kDa)

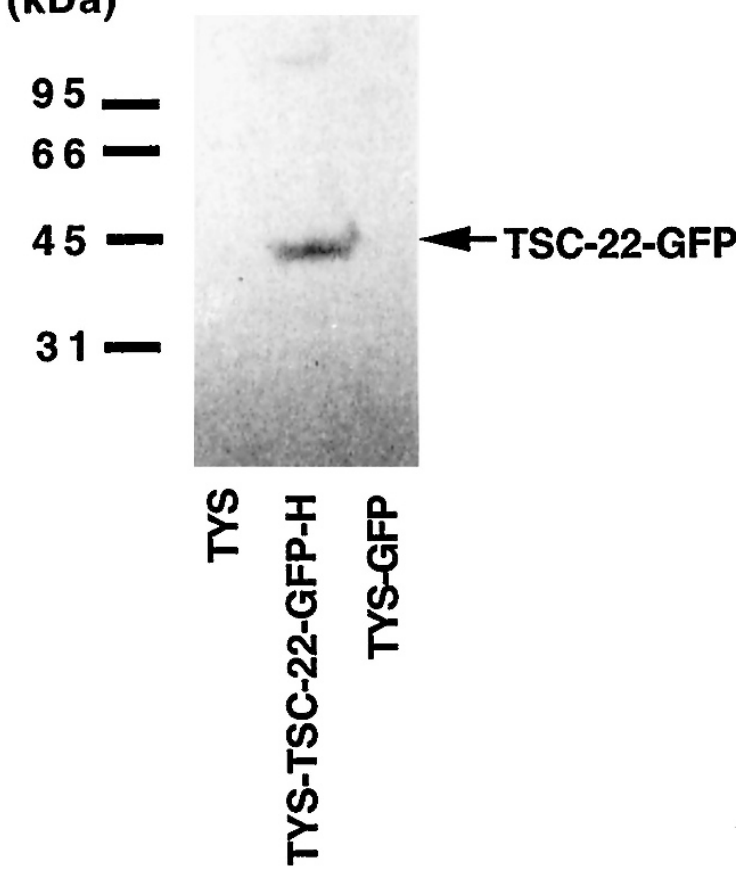

Figure 3.

Detection of TSC-22-GFP fusion protein by Western blotting. Forty micrograms of protein samples from parental TYS, TYS-GFP, and TYS-TSC-22-GFP-H were subjected to SDS-polyacrylamide gel electrophoresis, transferred to nitrocellulose, and stained with an affinity-purified rabbit anti-TSC-22 antibody and an Amersham ECL kit. Positions of molecular-weight markers $(\mathrm{kDa})$ are indicated. A clear band at $45 \mathrm{kDa}$ was observed only in TYS-TSC-22-GFP-H, but not in parental TYS or TYS-GFP. A very faint band at approximately $130 \mathrm{kDa}$ was also observed in TYS-TSC-22-GFP-H cells.

various levels of the transfected gene (sense or antisense TSC-22 cDNA). If some clones in the transfectants acquire a growth advantage by over-expression of the transfected gene, the growth of the transfectants seems to be enhanced by the transfection, as observed in our antisense TSC-22 transfectants. On the other hand, if the growth potential of some clones in the transfectants is suppressed by the transfected gene, growth suppression of these clones may be masked by the adjacent fast-growing cells, and the growth suppression of the transfectants could not be demonstrated. Furthermore, as we discussed in our previous paper, the artificial expression of only one negative growth regulator, TSC-22, was not sufficient to antagonize all of the growth-stimulatory factors in the logarithmic growth phase.

To solve the problems arising from the previous experiment, we conducted the present study as follows: (a) two clonal cells over-expressing TSC-22 protein at different levels were isolated and used for subsequent experiments; (b) for induction of several growth suppressors, or for reduction of the level of several growth stimulators, TSC-22-overexpressing clones were treated with anticancer drugs (5-FU, CDDP, and PEP), and growth suppression and the induction of apoptosis in the clones were examined; (c) to confirm the implication of the transfected TSC-22 gene for the growth suppression or the induc-
A

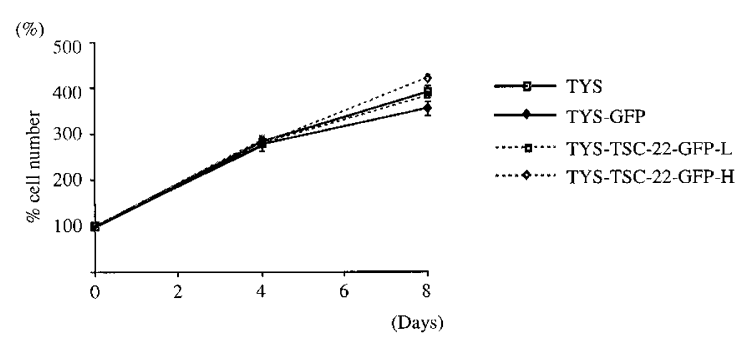

B
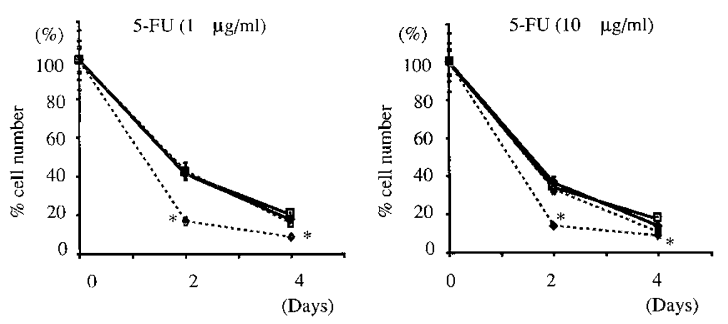

C
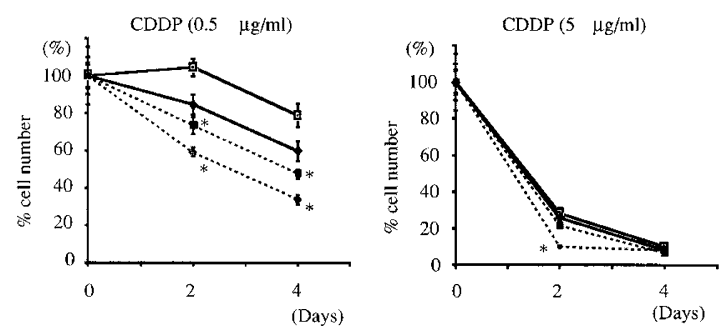

D
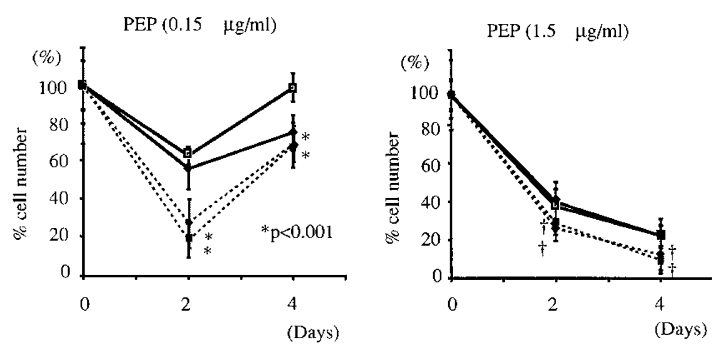

Figure 4.

In vitro chemosensitivity of cell clones. Relative cell number was evaluated in each cell clone at Day 0, Day 4, and Day 8 by comparison of the absorbance, which was determined by MTT assay. No significant difference was seen in the growth potential among the cell clones $(A)$. 5 -FU treatment $(1 \mu \mathrm{g} / \mathrm{ml}$ or 10 $\mu \mathrm{g} / \mathrm{ml}$ ) suppressed the growth of parental cells down to $20 \%$ at Day 2 and $10 \%$ at Day 4; however, most of the TYS-TSC-22-GFP-H cells were killed at Day 2 by treatment with $1 \mu \mathrm{g} / \mathrm{ml}$ or $10 \mu \mathrm{g} / \mathrm{ml}$ of $5-\mathrm{FU}(B)$. Low concentrations of CDDP $(0.5 \mu \mathrm{g} / \mathrm{ml})$ and PEP $(0.15 \mu \mathrm{g} / \mathrm{ml})$ markedly suppressed the growth of TYS-TSC-22-GFP-H and TYS-TSC-22-GFP-L cells, whereas they had only a slight effect on the parental TYS cells and control TYS-GFP cells $(C$ and $D)$. The values shown are the mean of six determinations. The error bars indicate the standard deviation. ${ }^{\star} p<0.001, \dagger p<0.01$ when compared with control cells and sense transfectants (one-way ANOVA).

tion of apoptosis, transfected over-expression of TSC-22 was blocked again by an antisense oligonu- 
Table 1. Chemosensitivity of Cell Clones

\begin{tabular}{lcccc}
\hline & & \multicolumn{3}{c}{ TYS-TSC-22- TYS-TSC-22- } \\
& Parental TYS & TYS-GFP & GFP-L & GFP-H \\
\hline 5-FU & $0.28^{*}$ & 0.30 & 0.35 & 0.03 \\
PEP & 1.84 & 2.18 & 0.48 & 0.57 \\
CDDP & 2.15 & 2.02 & 1.26 & 0.70 \\
\hline
\end{tabular}

*Values are shown by $I_{50}(\mu \mathrm{g} / \mathrm{ml})$. The $I_{50}$ was defined as drug concentration, which reduced the number of the cells by $50 \%$.

cleotide, and the recovery of the phenotype of the transfectants was examined. We found that overexpression of TSC-22 did not affect the growth of TYS cells in the presence or absence of FCS. However, over-expression of TSC-22 significantly $(p<0.01)$ enhanced the sensitivity of the cells to all of the anticancer drugs tested. Furthermore, overexpression of TSC-22 markedly enhanced 5-FUinduced apoptosis. These phenotypic alterations induced by the over-expression of TSC-22 were restored by treatment with an antisense oligonucleotide against the TSC-22 gene.

Ohta et al (1997) reported that over-expression of TSC-22 in a human gastric cancer cell line, HSC-39, induced apoptosis of the cells via activation of Caspase-3. They reported that, in HSC-39 cells, apoptosis was easily induced by treatment with TGF- $\beta 1$ (Ohta et al, 1997). However, in our human salivary gland cancer cells, over-expression of only TSC-22 did not induce apoptosis of TYS cells, but markedly enhanced the chemo-sensitivity of the cells to 5-FU, CDDP, and PEP. Susceptibility of the cells to apoptosis may be dependent upon the expression of other apoptosis-associated molecules in the cells.

The molecular mechanisms of the action of chemotherapeutic agents on cancer cells are not fully understood. It was well known that a tumor suppressor gene, p53, was frequently mutated in several types of malignant tumors, and that tumors harboring a mutated or deleted p53 gene showed significant chemoresistance to several chemotherapeutic agents when compared with tumors harboring wild-type p53 (Fujiwara et al, 1994; Lowe et al, 1994; Righetti et al, 1996). It was also reported that the introduction of the wild-type p53 gene into cancer cells markedly inhibited the growth of the cells, induced apoptosis, and enhanced the chemo-sensitivity of the cells (Cirielli et al, 1995; Fujiwara et al, 1994; Yang et al, 1995). Based on these basic findings, gene therapy, ie, the introduction of the wild-type p53 gene into tumors with a mutated or deleted p53 gene, has been started throughout the world (Roth et al, 1998; Schuler et al, 1998) including Japan. Recently, GPI-anchored molecule-like protein (GML) has been isolated as a p53-inducible gene (Kimura et al, 1997a; 1997b). The expression of GML was decreased in several esophagus cancer cells which showed chemo-resistance in vitro (Furuhata et al, 1996). It was also reported that over-expression of the GML gene enhanced not only the chemosensitivity, but also the radiosensitivity of esophagus cancer cells (Kagawa et al, 1997; Kimura et al, 1997a). Salivary gland tumors are well known to be chemo-resistant; thus, TSC-22 can be utilized as a chemo-sensitizer not only for salivary gland tumors, but also for various chemo-resistant tumors in other organs.

Another major result of this experiment is that we clearly demonstrated the cytoplasmic localization of TSC-22 protein. As we described in our previous paper (Nakashiro et al, 1998), we attempted to detect the localization of TSC-22 protein in TYS cells by immunohistochemistry, using an anti-TSC-22-GST fusion protein antibody. However, we failed to demonstrate the clear localization of TSC-22 protein in parental TYS cells as well as in TSC-22-over-expressing TYS cells.

For a further understanding of the function of TSC22 , it is essential to know the localization of the TSC-22 protein and its molecular kinetics after several extracellular stimulations. Shibanuma et al (1992) reported that TSC-22 protein was detectable not only in the cytoplasm but also in the nucleus in mouse MC3T3E1 cells by immunohistochemistry with a polyclonal antibody that was made against bacterial recombinant mouse TSC-22. On the other hand, Ohta et al (1997) reported that haemagglutinin-tagged TSC-22 was detected only in the nucleus in apoptosis-induced human gastric cancer cells by an antihaemagglutinin antibody. Treisman et al (1995) demonstrated a clear cytoplasmic localization of Drosophila shortsighted protein. Thus, the subcellular localization of TSC-22 has not yet been clarified. In this experiment, we clearly demonstrated the cytoplasmic localization of TSC-22 protein, and recently we found that TSC-22 protein translocates from cytoplasm to nucleus after 5-FU treatment concomitant with the induction of apoptosis (S. Hino, D. Uchida, F. Omotehara, Y. Miwa, N-M. Begum, H. Yoshida, M. Sato, and H. Kawamata, unpublished data). Taking the previous reports and our findings together, TSC-22 protein may exist in the cytoplasm under static conditions and alter its subcellular localization after induction of apoptosis.

It still remains necessary to examine the molecular mechanisms of the action of the TSC-22 protein after anticancer drug treatment. As reported previously, TSC-22 has a leucine zipper structure and two putative phosphorylation sites by protein kinase $\mathrm{C}$ and casein kinase II, respectively (Kawamata et al, 1998; Shibanuma et al 1992). It could be speculated that, after phosphorylation of TSC-22 protein in the cytoplasm by several apoptosis-inducing signals, TSC-22 binds to some proteins, presumably transcription factors, by their leucine zipper and translocates from the cytoplasm to the nucleus by the nuclear localization signal of the bound proteins. Thus, TSC-22 may inhibit or stimulate the transcriptional activity of the bound proteins and may induce apoptosis. In order to prove our hypothesis, we must identify the TSC-22-binding proteins. As shown in the result of Western blotting (Fig. 3), a high-molecular-weight band (approximately $130 \mathrm{kDa}$ ) is always detected by anti-TSC-22-GST antibody. The high-molecular-weight band might be a 


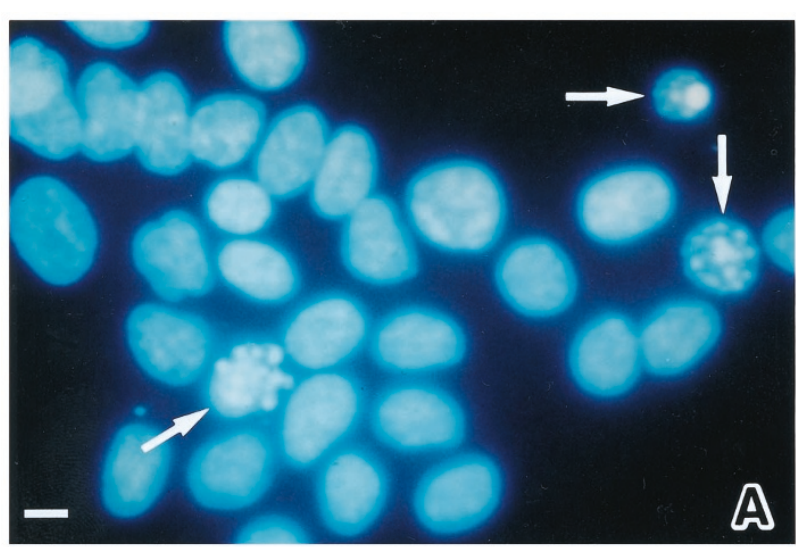

C

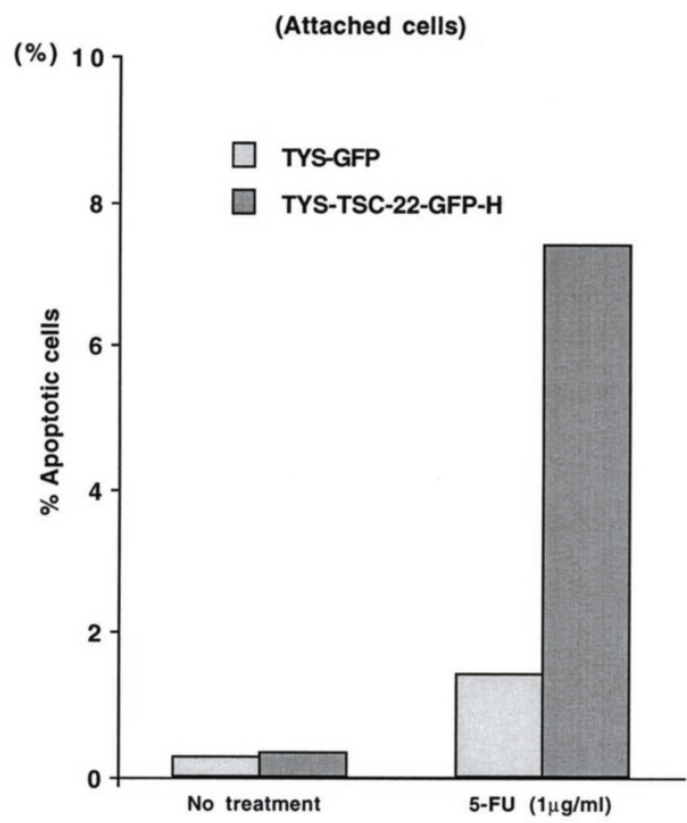

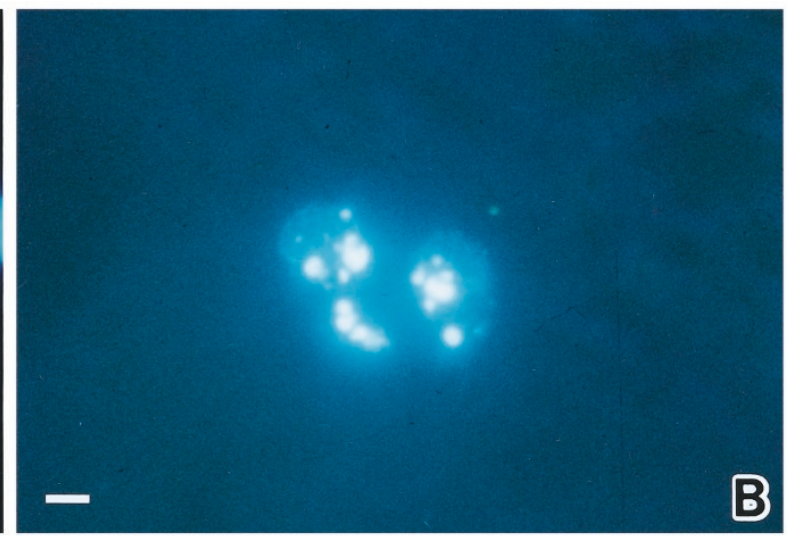

D

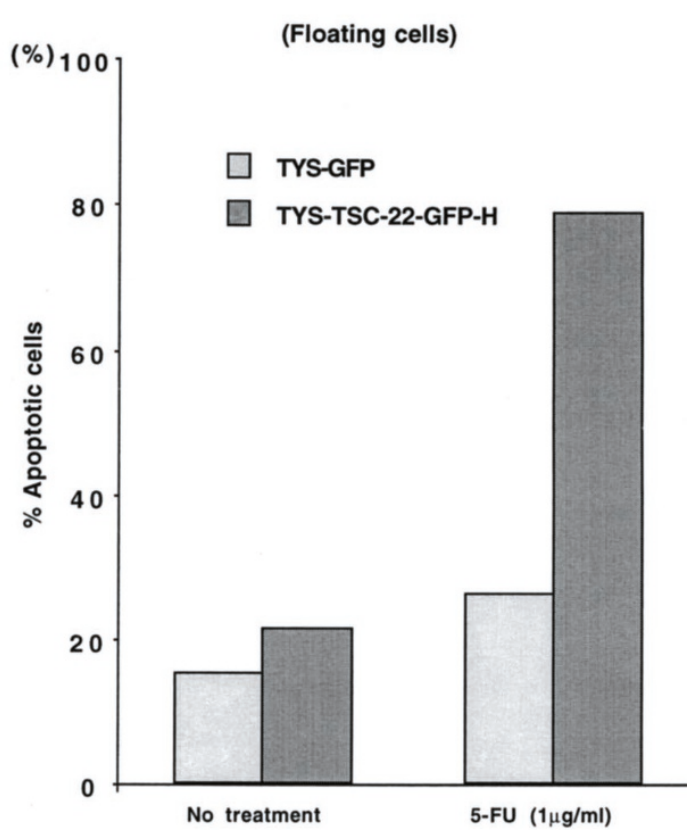

\section{Figure 5.}

Induction of apoptosis in 5-FU-treated cells. Of the attached cells, 8\% of TYS-GFP-22-GFP-H cells showed chromatin condensation (arrows in $A$, and Graph C) after treatment with $1 \mu \mathrm{g} / \mathrm{ml}$ of 5 -FU for 24 hours, whereas only $2 \%$ of control TYS-GFP cells showed chromatin condensation $(C)$. Of the floating cells, $80 \%$ of TYS-GFP-22-GFP-H cells showed chromatin condensation ( $B$, and Graph $D$ ), whereas only $20 \%$ of control TYS-GFP cells showed chromatin condensation (D). $A$ and $B$, Cells were stained by Hoechst 33258. Bar, $8 \mu \mathrm{m}$.

complex of TSC-22 and its binding protein or a protein that has a similar epitope to TSC-22.

Thus, TSC-22 appears to be a regulatory gene for cell growth, differentiation, and apoptosis. If the precise function of TSC-22 is clarified, TSC-22 can be used as a molecular target for diagnosis and therapy of salivary gland and other cancers.

\section{Materials and Methods}

\section{Cell Culture}

TYS cells were grown in Dulbecco's modified Eagle medium (DMEM; Life Technologies, Inc., Rockville, Maryland) supplemented with $10 \%$ fetal calf serum (FCS; BioWhittaker, Walkersville, Maryland), 100 $\mu \mathrm{g} / \mathrm{ml}$ streptomycin, $100 \mathrm{U} / \mathrm{ml}$ penicillin (Life Technol- ogies, Inc.), and $0.25 \mu \mathrm{g} / \mathrm{ml}$ amphotericin B (Life Technologies, Inc.) in a humidified atmosphere of $95 \%$ air and $5 \% \mathrm{CO}_{2}$ at $37^{\circ} \mathrm{C}$ (Yanagawa et al, 1986).

\section{Construction of a Mammalian Expression Vector}

The mammalian expression vector pEGFP-TSC-22, containing the GFP-human TSC-22 fusion gene (Fig. 1), was constructed as follows: pEGFP-C3 (Clontech, Palo Alto, California) (Yang et al, 1996) is a mammalian expression vector containing the enhanced GFP gene under the transcriptional control of the cytomegalovirus immediate early promoter (CMV-IE). pEGFP-C3 was digested with EcoRI (Takara Biomedicals, Kusatsu, Japan) and Sall (Takara Biomedicals). The human TSC-22 cDNA fragment was amplified from 
A

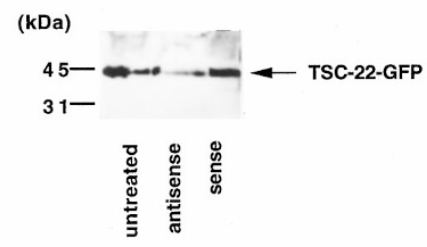

B

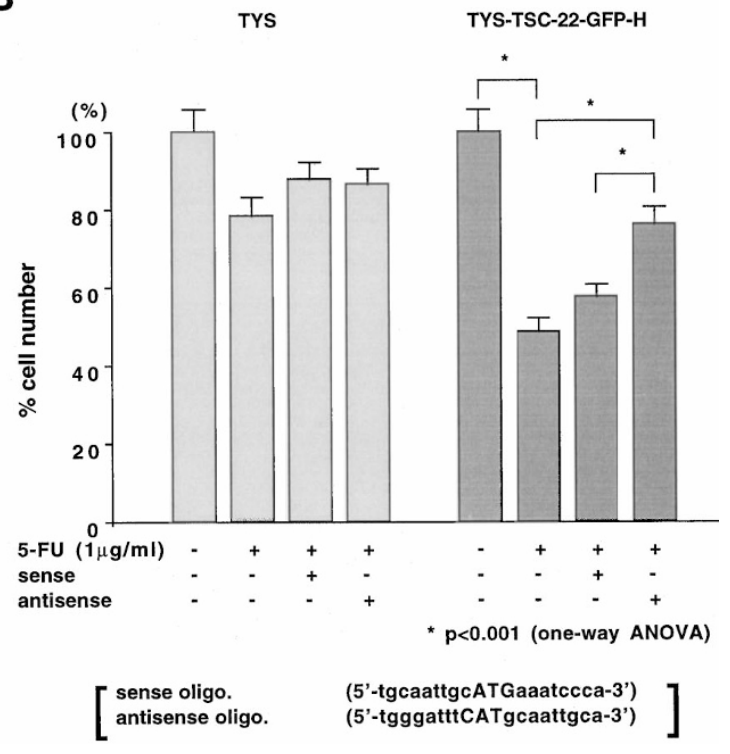

Figure 6.

Effect of an antisense oligonucleotide against the TSC-22 gene on TYS-TSC22-GFP cells. A, TYS-TSC-22-GFP cells were treated with $30 \mu \mathrm{m}$ oligonucleotides for 24 hours, and cell lysates were subjected to Western blotting. The expression of transfected TSC-22-GFP protein in TYS-TSC-22-GFP-H cells was clearly inhibited by treatment with an antisense oligonucleotide. B. TYS-TSC22-GFP-H cells were seeded on 96-well plates, at $1 \times 10^{4}$ cells per well, in DMEM containing $10 \%$ FCS. Twenty-four hours later, the medium was changed to DMEM containing $10 \mu \mathrm{m}$ oligonucleotides without FCS, and the cells were pre-incubated for 24 hours in the presence of oligonucleotides. Next, 5 -FU was added to the medium at $1 \mu \mathrm{g} / \mathrm{ml}$. After 48 hours of 5 - FU treatment, the number of cells was quantitated by MTT assay. 5 -FU $(1 \mu \mathrm{g} / \mathrm{ml})$ treatment inhibited the growth of TYS-TSC-22-GFP-H cells down to $50 \%$ of control at Day 2; however, the antisense oligonucleotide restored the cell number up to $80 \%$ of control even in the presence of 5 -FU. On the other hand, the antisense oligonucleotide marginally influenced the effect of 5-FU on parental TYS cells.

pUC19-hTSC-22 (Kawamata et al, 1998) by use of a pair of specific primers, FP22-UP (5'-GGAATTCCCA TGAAATCCCAATG-3') and FP22-DW (5'-GGTCGAC CTATGCGGTGGTCCTG-3'). This fragment, containing the human TSC-22 open reading frame, the EcoRI site at the $5^{\prime}$ end, and the Sall site at the $3^{\prime}$ end, was ligated to the cloning site, which was localized downstream of the GFP gene of pEGFP-C3. The direction of the ligated fragment from the CMV-IE promoter was confirmed by sequencing analysis with a specific primer (TSC-SQP1; 5'-ATCGCAGGGCTCAGGACCAA$\left.3^{\prime}\right)$ for human TSC-22 cDNA. The DNA sequence was determined by the dideoxy chain termination method, using fluorecein-labeled primers and a Thermo Sequenase Cycle sequencing kit (Amersham Pharmacia Biotech, Uppsala, Sweden). Electrophoresis and scanning were performed with a Shimadzu DSQ-500 DNA sequencer (Shimadzu, Kyoto, Japan).

\section{Transfection}

TYS cells $\left(5 \times 10^{5}\right.$ cells/dish) were seeded in $100 \mathrm{~mm}$ culture dishes (Falcon; Becton Dickinson Labware, Lincoln Park, New Jersey) in DMEM supplemented with $10 \%$ FCS. Twenty-four hours later, the cells were transfected with $5 \mu \mathrm{g}$ of pEGFP-TSC-22 by use of the Superfect reagent (Qiagen, Hilden, Germany). The cells were incubated for 24 hours in DMEM containing $10 \%$ FCS, then trypsinized and seeded at a 1:5 ratio in $100 \mathrm{~mm}$ culture dishes in DMEM medium containing $10 \%$ FCS. Forty-eight hours later, the cells were switched to a selective medium containing Geneticin $(800 \mu \mathrm{g} / \mathrm{ml} \mathrm{G} 418$, Life Technologies, Inc.). After 14 days of culture in the selective medium, eight representative G418-resistant clones were isolated and expanded in a 24-well cluster dish (Falcon).

\section{Western Blotting}

Cell lysates were prepared from the transfectants as follows: cells were cultured to subconfluence, washed three times with $100 \mathrm{~mm}$ phosphate-buffered-saline, and lysed with $50 \mathrm{~mm} \mathrm{~N}$-2-hydroxyethyl piperazine$\mathrm{N}^{\prime}$-2-ethanesulfonic acid, HEPES ( $\mathrm{pH}$ 7.5) containing $150 \mathrm{~mm} \mathrm{NaCl}, 1 \%$ Triton X-100, $1.5 \mathrm{~mm} \mathrm{MgCl}, 1 \mathrm{~mm}$ EDTA, $10 \mathrm{~mm}$ sodium pyrophosphate, $100 \mathrm{~mm}$ sodium orthovanadate, $100 \mathrm{~mm} \mathrm{NaF}, 100 \mathrm{~mm}$ p-nitrophenyl phosphate, $5 \mathrm{U} / \mathrm{ml}$ aprotinin, and $1 \mathrm{~mm}$ phenyl-methylsulfonyl fluoride. The protein concentration of the samples was determined by Bio-Rad protein assay (Bio-Rad, Hercules, California). Forty micrograms of protein samples were electrophoresed on SDS-polyacrylamide gel. Proteins from gels were transferred to nitrocellulose (Bio-Rad), and the membrane was incubated with affinity-purified anti-TSC-22 antibody (Nakashiro et al, 1998) and an Amersham ECL kit (Amersham Pharmacia Biotech).

\section{MTT Assay}

Cells were seeded on 96-well plates (Falcon) at $1 \times$ $10^{4}$ cells per well in DMEM containing $10 \%$ FCS. After 2 and 4 days, the number of cells was quantitated by an assay in which MTT (Sigma Chemical Company, St. Louis, Missouri) was used (Carmichael et al 1987).

\section{Chemo-Sensitivity of the Transfectants}

Cells were seeded on 96-well plates at $5 \times 10^{3}$ cells per well in DMEM containing 10\% FCS. Twenty hours later, the medium was changed to DMEM containing three anticancer drugs: $5-\mathrm{FU}(1,10 \mu \mathrm{g} / \mathrm{ml}), \operatorname{CDDP}(0.5$, $5 \mu \mathrm{g} / \mathrm{ml})$, and PEP $(0.15,1.5 \mu \mathrm{g} / \mathrm{ml})$, in the absence of FCS. After 2 and 4 days, the number of cells was quantitated by MTT assay. 
To determine $\mathrm{IC}_{50}$, cells were cultured in DMEM containing three anticancer drugs: $5-\mathrm{FU}(0.001,0.01$, $0.1,1,10 \mu \mathrm{g} / \mathrm{ml}), \operatorname{CDDP}(0.05,0.10 .5,1,5 \mu \mathrm{g} / \mathrm{ml})$, and PEP $(0.015,0.15,0.5,1.5,5 \mu \mathrm{g} / \mathrm{ml})$, in the absence of FCS. After 2 days, the number of cells was quantitated by $\mathrm{MTT}$ assay. The $\mathrm{IC}_{50}$ was calculated as drug concentration, which reduced the number of the cells by $50 \%$.

\section{Green Fluorescent Protein Fluorescence}

Cells $\left(5 \times 10^{3}\right)$ were seeded on cover-glasses in 35 $\mathrm{mm}$ culture dishes (Falcon) in DMEM containing 10\% FCS. Twenty hours later, the cover-glasses with the cells were washed with $100 \mathrm{~mm}$ phosphate-bufferedsaline and placed on slides. GFP fluorescence was observed by fluorescence microscopy (Nikon, Tokyo, Japan) excited by $495 \mathrm{~nm}$ blue light.

\section{Detection of Apoptotic Cells after Treatment with 5-FU}

Cells $\left(5 \times 10^{3}\right)$ were seeded on cover-glasses in 35 $\mathrm{mm}$ culture dishes in DMEM containing 10\% FCS. After treatment with 5-FU $(1 \mu \mathrm{g} / \mathrm{ml})$ for 48 hours, floating cells were collected in microcentrifuge tubes. Next, floating cells and attached cells on the coverglasses were fixed with acetic acid:methanol (1:3) and stained with Hoechst 33258, 500 ng/ml (Flow Laboratories, Inc., McLean, Missouri), for 30 minutes. Hoechst fluorescence was observed by fluorescence microscopy excited by $365 \mathrm{~nm}$.

\section{Treatment of the Transfectants with Antisense Oligonucleotide against the Human TSC-22 Gene}

An anti-sense phosphorothioate oligonucleotide (5'TGGGATTTCATGCAATTGCA-3') and a sense phosphorothioate oligonucleotide (5'-TGCAATTGCATG AAATCCCA-3') were synthesized (Kawamata et al, 1998). First, we examined the down-regulation of the TSC-22-GFP fusion protein in TYS-TSC-22-GFP-H cells by treatment with the antisense oligonucleotide. Cells $\left(5 \times 10^{4}\right)$ were seeded on $35 \mathrm{~mm}$ culture dishes in DMEM containing 10\% FCS. Twenty-four hours later, the medium was changed to DMEM containing $30 \mu \mathrm{m}$ oligonucleotides without FCS, and the cells were incubated for 24 hours in the presence of oligonucleotides. Then cell lysates were prepared by the method described above and were subjected to Western blotting. Next, we analyzed the effect of the antisense oligonucleotide on growth suppression by 5-FU on TSC-22-GFP-expressing cells. Cells were seeded on 96 -well plates at $1 \times 10^{4}$ cells per well in DMEM containing 10\% FCS. Twenty-four hours later, the medium was changed to DMEM containing $10 \mu \mathrm{m}$ oligonucleotides without FCS, and the cells were pretreated with oligonucleotides for 24 hours. Next, $5-\mathrm{FU}$ was added to the medium at $1 \mu \mathrm{g} / \mathrm{ml}$. After 48 hours of 5-FU treatment, the number of cells was quantitated by MTT assay.

\section{References}

Carmichael J, DeGraff WG, Gazdar AF, Minna JD, and Mitchell JB (1987). Evaluation of a tetrazolium-based semiautomated calorimetric assay: Assessment of chemosensitivity testing. Cancer Res 47:936-942.

Cirielli C, Riccioni T, Yang C, Pili R, Gloe T, Chang J, Inyaku K, Passaniti A, and Capogrossi MC (1995). Adenovirusmediated gene transfer of wild-type p53 results in melanoma cell apoptosis in vitro and in vivo. Int $\mathrm{J}$ Cancer 27:673-679.

Dobens LL, Hsu T, Twombly V, Gelbart WM, Raftery LA, and Kafatos FC (1997). The Drosophila bunched gene is a homologue of the growth factor stimulated mammalian TSC-22 sequence and is required during oogenesis. Mech Dev 65: 197-208.

Fujiwara T, Grimm EA, Mukhopadhyay T, Zhang WW, OwenSchaub LB, and Roth JA (1994). Induction of chemosensitivity in human lung cancer cells in vivo by adenovirus-mediated transfer of the wild-type p53 gene. Cancer Res 54:22872291.

Furuhata T, Tokino T, Urano T, and Nakamura Y (1996). Isolation of a novel GPI-anchored gene specifically regulated by $\mathrm{p} 53$; correlation between its expression and anti-cancer drug sensitivity. Oncogene 13:1965-1970.

Hamil KG and Hall SH (1994). Cloning of rat Sertoli cell follicle-stimulating hormone primary response complementary deoxyribonucleic acid: Regulation of TSC-22 gene expression. Endocrinology 134:1205-1212.

Jay P, Ji JW, Marsollier C, Taviaux S, Berge-Lefranc JL, and Berta $P$ (1996). Cloning of the human homologue of the TGF- $\beta$-stimulated clone 22 gene. Biochem Biophys Res Commun 222:821-826.

Kagawa K, Inoue T, Tokino T, Nakamura $\mathrm{Y}$, and Akiyama T (1997). Overexpression of GML promotes radiation-induced cell cycle arrest and apoptosis. Biochem Biophys Res Commun 241:481-485.

Kania A, Salzberg A, Bhat M, D'Evelyn D, He Y, Kiss I, and Bellen HJ (1995). P-element mutations affecting embryonic peripheral nervous system development in Drosophila melanogaster. Genetics 139:1663-1678.

Kawamata H, Nakashiro K, Uchida D, Hino S, Omotehara F, Yoshida H, and Sato M (1998). Induction of TSC-22 by treatment with a new anti-cancer drug, Vesnarinone, in a human salivary gland cancer cell. Br J Cancer 77:71-78.

Kester H A, van der Leede BM, van der Saag PT, and van der Burg B (1997). Novel progesterone target genes identified by an improved differential display technique suggest that progestin-induced growth inhibition of breast cancer cells coincides with enhancement of differentiation. J Biol Chem 272:16637-16643.

Kimura Y, Furuhata T, Shiratsuchi T, Nishimori H, Hirata K, Nakamura Y, and Tokino T (1997a). GML sensitizes cancer cells to Taxol by induction of apoptosis. Oncogene 15:13691374.

Kimura Y, Furuhata T, Urano T, Hirata K, Nakamura Y, and Tokino T (1997b). Genomic structure and chromosomal localization of GML (GPI-anchored molecule-like protein), a gene induced by p53. Genomics 41:477-480.

Lowe SW, Bodis S, McClatchey A, Remington L, Ruley HE, Fisher DE, Housman DE, and Jacks T (1994). p53 status and the efficacy of cancer therapy in vivo. Science $266: 807-810$. 
Nakashiro K, Kawamata H, Hino S, Uchida D, Miwa Y, Hamano H, Omotehara F, Yoshida H, and Sato M (1998). Down-regulation of TSC-22 (transforming growth factor $\beta$-stimulated clone 22) markedly enhances the growth of a human salivary gland cancer cell line in vitro and in vivo. Cancer Res 58:549-555.

Ohta S, Shimekake Y, and Nagata K (1996). Molecular cloning and characterization of a transcription factor for the C-type natriuretic peptide gene promoter. Eur J Biochem 242:460-466.

Ohta S, Yanagihara K, and Nagata K (1997). Mechanism of apoptotic cell death of human gastric carcinoma cells mediated by transforming growth factor $\beta$. Biochem J 324:777782 .

Righetti SC, Della-Torre G, Pilotti S, Menard S, Ottone F, Colnaghi MI, Pierotti MA, Lavarino C, Cornarotti M, Oriana S, Bohm S, Bresciani GL, Spatti G, and Zunino F (1996). A comparative study of p53 gene mutations, protein accumulation, and response to cisplatin-based chemotherapy in advanced ovarian carcinoma. Cancer Res 56:689-693.

Roth JA, Swisher SG, Merritt JA., Lawrence DD, Kemp BL, Carrasco CH, El-Naggar AK, Fossella FV, Glisson BS, Hong WK, Khurl FR, Kurie JM, Nesbitt JC, Pisters K, Putnam JB, Schrump DS, Shin DM, and Walsh GL (1998). Gene therapy for non-small cell lung cancer: a preliminary report of a phase I trial of adenoviral p53 gene replacement. Semin Oncol 25:33-37.

Schuler M, Rochlitz C, Horowitz JA, Schlegel J, Perruchoud AP, Kommoss F, Bolliger CT, Kauczor HU, Dalquen P, Fritz MA, Swanson S, Herrmann R, and Huber C (1998). A phase I study of adenovirus-mediated wild-type p53 gene transfer in patients with advanced non-small cell lung cancer. Hum Gene Ther 9:2075-2082.
Shibanuma M, Kuroki T, and Nose K (1992). Isolation of a gene encoding putative leucine zipper structure that is induced by transforming growth factor $\beta 1$ and other growth factors. J Biol Chem 267:10219-10224.

Sillard R, Schulz-Knappe P, Vogel P, Raida M, Bensch KW, Forssmann WG, and Mutt V (1993). A novel 77-residue peptide from porcine brain contains a leucine-zipper motif and is recognized by an antiserum to delta-sleep-inducing peptide. Eur J Biochem 216:429-435.

Treisman JE, Lai ZC, and Rubin GM (1995). Shortsighted acts in the decapentaplegic pathway in Drosophila eye development and has homology to a murine TGF- $\beta$-responsive gene. Development 121:2835-2845.

Vogel P, Mägert HJ, Cieslak A, Adermann K, and Forssmann WG (1996). hDIP-a potential transcriptional regulator related to murine TSC-22 and Drosophila shortsighted (shs)-is expressed in a large number of human tissues. Biochim Biophys Acta 1309:200-204.

Yanagawa T, Hayashi $Y$, Yoshida H, Yura Y, Nagamine S, Bando T, and Sato M (1986). An adenoid squamous carcinoma-forming cell line established from an oral keratinizing squamous cell carcinoma expressing carcinoembryonic antigen. Am J Pathol 124:496-509.

Yang C, Cirielli C, Capogrossi MC, and Passaniti A (1995). Adenovirus-mediated wild-type p53 expression induces apoptosis and suppresses tumorigenesis of prostatic tumor cells. Cancer Res 55:4210-4213.

Yang TT, Cheng L, and Kain SR (1996). Optimized codon usage and chromophore mutations provide enhanced sensitivity with the green fluorescent protein. Nucleic Acids Res 24:4592-4593. 